\title{
GRID FREQUENCY CONTROL USING STEP RESPONSE IN FREE GOVERNOR MODE OF OPERATION
}

\author{
A.Nandhini ${ }^{1}$ C.Deviabirami ${ }^{2}$ A.Manikandan ${ }^{3}$ \\ ${ }^{1}$ M.E, Power Systems Engineering, Kalaignar Karunanidhi Institute of Technology, Tamilnadu, India \\ ${ }^{2}$ M.E, Power Systems Engineering, Kalaignar Karunanidhi Institute of Technology, Tamilnadu, India \\ ${ }^{3}$ M.E, Power Systems Engineering, Kalaignar Karunanidhi Institute of Technology, Tamilnadu, India
}

\begin{abstract}
In an interconnected power system, as a power load demand varies randomly; both area frequency and tie-line power interchange also vary. The objectives of load frequency control (LFC) are to minimize the transient deviations in these state errors to be zeros. When dealing with the LFC problem of power systems, unexpected external disturbances, parameter uncertainties and the model uncertainties of the power system cause big challenges for controller design. Maintaining power system frequency at constant value is very important for the health of the power generating equipment and the utilization equipment at the customer end. The job of automatic frequency regulation is achieved by governing systems of individual turbine-generators and Automatic Generation Control $(A G C)$ or Load frequency control system of the power system. Frequency regulation is one of the distribution services to be supplied by the electricity market participants. The only way to regulate frequency is to maintain the balance between demand and supply in real time.
\end{abstract}

Keywords: Load Frequency Control, FGMO, AGC, PWM, Step response.

***

\section{INTRODUCTION}

In India, it is achieved through a regulatory approach. In this concept, an investigation is made on Free Governor Mode of Operation to demonstrate Frequency Regulation by adopting Free Governor Mode of Operation. Simulation is also used to tune the controller gains or to design a control system .Our project deals with stabilizing the load frequency using microcontroller. The overall operation of power system can be much better controlled if the frequency error is kept within particular limits.

The acceptable limit of frequency is $\pm 2 \%$. Else it will damage the electrical and electronic equipment. Drop in frequency occurs due to high magnetizing currents in induction machines and transformers. To prevent the problems there is a need of Load Frequency Control.

As per the CERC (Central Electricity Regularity Commission), New Delhi represents all Power Stations to control the generator load is based on the changes of grid frequency. If the Grid frequency decreases, the generator load will increases by the step response input based on the grid frequency variation. If the Grid frequency increases, the generator load will decreases by the step response input based on the grid frequency variation. But, the Grid frequency not in account, because the frequency is common factor of all generator connected to the grid system. As per the mechanical machine design of turbine, the Generator load control system based on the pressure deviation and output as step response to control the speeder gear motor rotations.

\section{FREE GOVERNOR MODE}

The developing countries have sustained power shortage problems compared to developed countries for many reasons, mostly financial in nature. The developed countries have to address the power deficient areas occasionally. The deficient systems have typical features like frequency deviations, abrupt arising of deficiencies of power, low voltages and lack of coordination among constituents under a region due to indiscipline actions. In India speed governors have been prevented from responding by the utilities, with dead band configuring from $47.5 \mathrm{~Hz}$ to $51.5 \mathrm{~Hz}$. Emergency unloading of a unit is available only when frequency reaches $51.5 \mathrm{~Hz}$. As a consequence excursions in frequency are common up to $1 \mathrm{~Hz}$ in a time block of 15 minutes. For the sake of better control efforts are being made to enable the frequency governors to respond to entire range of frequency. This is called free governor mode of operation (FGMO).

\section{NEED FOR THE GOVERNING SYSTEM}

The load on the turbo-generator does not remain constant but vary as per the consumer demand. The presence of a perpetual mismatch between the generation and the demand in larger network results into variations in frequency and necessitates a continuous adjustment of generation at generator. 


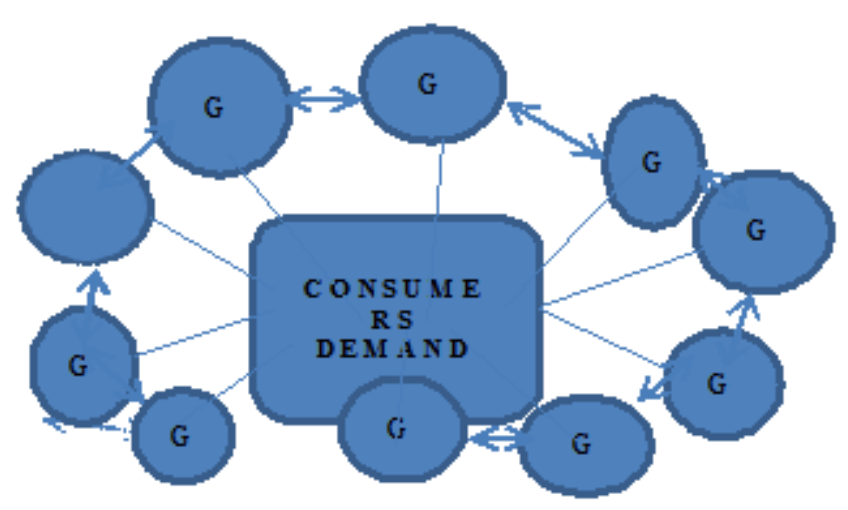

Fig -1 Generation VS Demand

Where $\mathrm{G}=$ generation of particular unit in a power plant Generation $=100 \mathrm{MW}$

Totally 10 generators,

GENERATION $=100 * 10=1000 \mathrm{MW}$

IF DEMAND $=1000 \mathrm{MW}$, FREQUENCY $=50 \mathrm{HZ}$

IF DEMAND $>1000 \mathrm{MW}$, FREQUENCY $<50 \mathrm{HZ}$

IF DEMAND $<1000 \mathrm{MW}$, FREQUENCY $>50 \mathrm{HZ}$

IF GENERATION $=100 * 9=900 \mathrm{MW}, \mathrm{BUT}$

DEMAND=1000 MW, FREQUENCY $<50 \mathrm{HZ}$

If not, the speed / frequency will be oscillating which is an indication of poor power quality. A state of unchanging system frequency and zero acceleration indicates that the generation meets the system demand. The governing system provides for this regulation / adjustment, when the turbo-generator is on bars, by controlling the steam in flow to the turbine. The regulation is envisaged by various control logics and by operating the control valves in the turbine. Stop valves provided in the governing system protect the turbine in case of unsafe conditions by blocking the steam flow into the turbine.

\section{PWM MODEL}

The saturated main steam as derived from Boiler at 130 $\mathrm{Kg} / \mathrm{cm}^{2}$ Pressure and $650 \mathrm{~T} / \mathrm{Hr}$ quantity of Steam are fed into the HP Turbine through 4 No's of control valves. These control valves are operated by Hydraulic cylinder. The Hydraulic cylinder mechanism is called as Control Valve Servo Mechanism (CVSM). The input Oil pressure of CVSM is increased or decreased, that control valves are opened or closed. The Main Oil Pump is placed on front pedestal of HP turbine, which is supply to the Lubricating oil of turbine bearings and CVSM of HP turbine pressure control at constant pressure at $1.2 \mathrm{Kg} / \mathrm{cm}^{2}$. Speeder Gear servo motor is placed on top of Main oil pump, which motor is used to increase or decrease the oil pressure of CVSM of HP turbine pressure control valves. If servo motor to rotate forward pulse, the oil pressure of CVSM is increased further the control valves are opening and Main steam admitted to Turbine blades are increased.

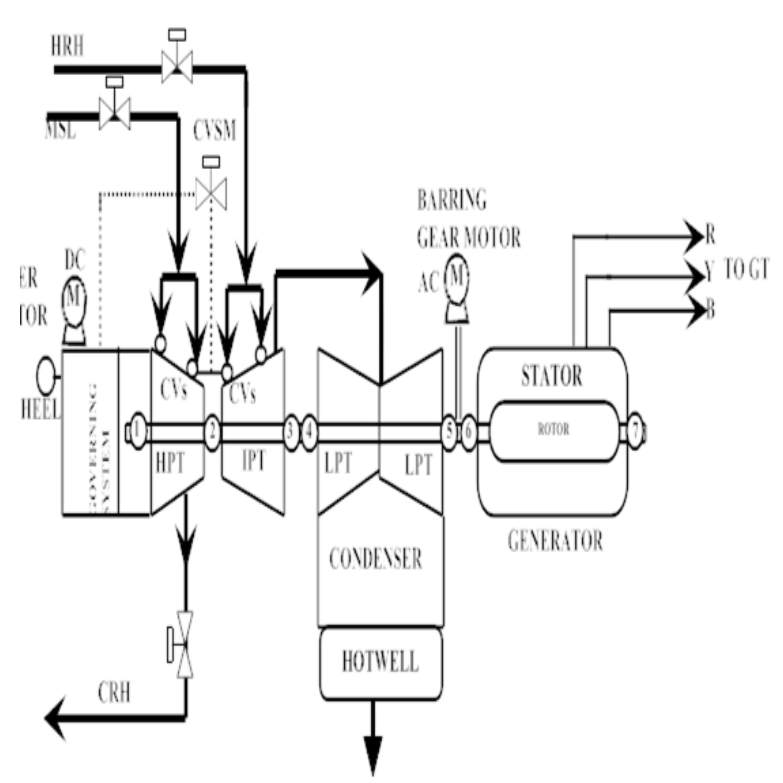

Fig-2 Layout diagram of control valve

The turbine shaft torque output is increased. So Generator Electrical output (MW) also increased In this Condition, main steam pressure of turbine input is decreased. If servo motor to rotate reverse pulse, the oil pressure of CVSM is decreased further the control valves are closing and Main steam admitted to Turbine blades are decreased. The turbine shaft torque output is decreased. So Generator Electrical output (MW) also decreased. In this Condition, main steam pressure of turbine input is increased. That operation is possible on manually by increase or decrease by servo motor operating push buttons. The manual operation is not possible at all time's exclusive odd hours.

So, servo motor operation in auto operation of desired main steam pressure out of boiler. The closed loop control system of servo motor operation is possible at main steam pressure desired set value and process value of steam output of boiler. The control loop logics as derived from macro method logic in microprocessor and related input output electronic cards. In the control logics the steam pressure Set value and Process value deviation output as Pulse width modulation (PWM) format. Pulse width of PWM output signal is based on the deviation of SV \& PV deviation. The automatic closed loop operation is possible at maximum and minimum level of steam pressure deviation. If deviation is more than $+/-3.5 \mathrm{Kg} / \mathrm{cm}^{2}$ the auto loop control goes to forced manual condition. In this condition the Generator operator to operate manually byincrease or decrease push button of servo motor operation and control the main steam pressure at equal to the set value of pressure and put into auto mode operation. 


\section{STEP RESPONSE METHOD}

Any deviation in the grid frequency the generator load gives the sudden response for proportional error pulse. This affects the power system equipment's day by day and also reduces the efficiency of the equipment.

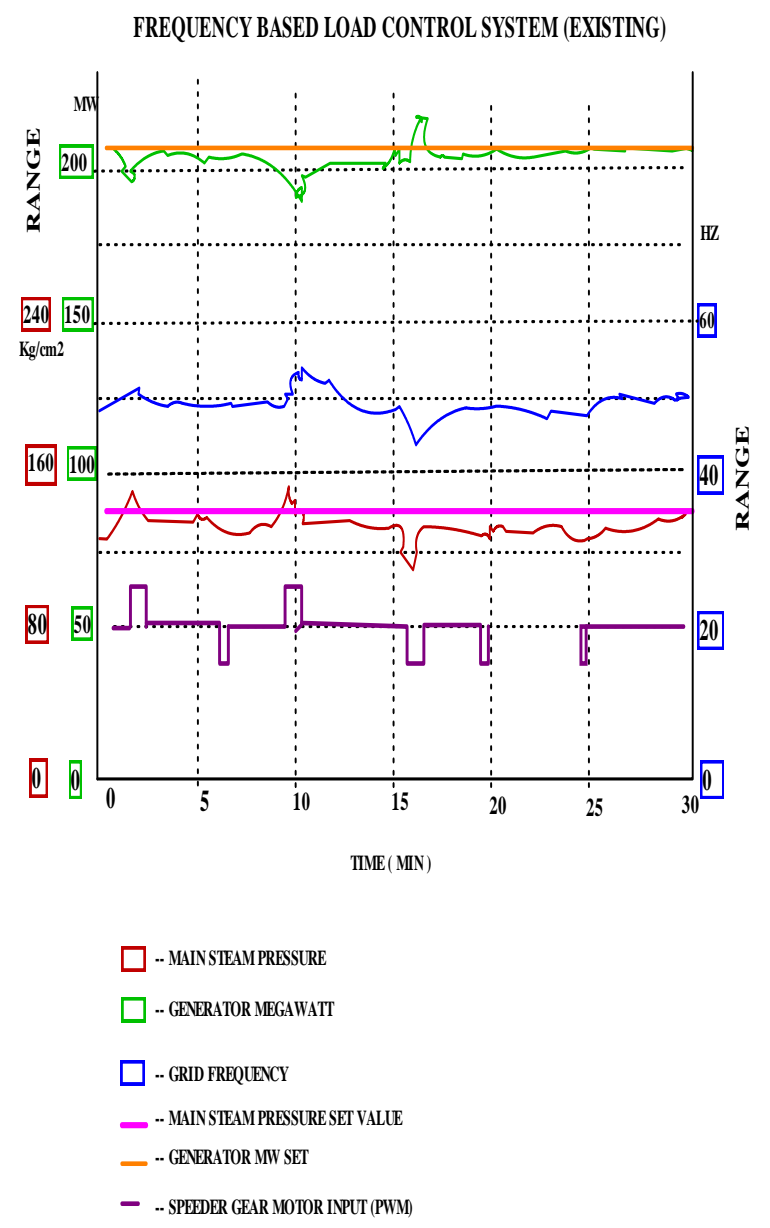

Fig- 3 Graphical Representation of Existing System

In this existing system the generation of power will get varied in large amount, when there is any deviation in the grid. It will take maximum time to attain the standard frequency, which leads to damaging of consumers equipment's and also increases the demand and also disturbing the Grid stability.

In this paper using embedded system that is PIC microcontroller. The sudden frequency Change in grid, generator to response the load in step response with maintaining the desired steam pressure and steam flow. In this technique step response is obtained by the time delays, given through programming to the microcontroller. The objective of the project is to restore the frequency against the sudden load change. As a result this technique overcomes the disadvantage of the PWM based load control.
Increasing the power demand highlights the importance of the power generation and transmission is to supply the reliable electrical energy to the consumers. Our project deals with the efficient control of power plant using embedded technology. Depending on the current drawl, the generator load may vary from 0 to $\max (0$ to $210 \mathrm{MW}$ ). This means that the turbine must be provided with devices capable of adjusting the mechanical work on turbine shaft within the limits. Besides, what ever be the load, the turbine must maintain constant speed of driven generator since slight change in the generator speed changes the frequency of the alternating current produced. The load carried by the turbine and rate of steam flow through it changes during operation.

\section{BLOCK DIAGRAM DESCRIPTION}

Step down transformer is used to step down the voltage from $230 \mathrm{~V}$ AC into $12 \mathrm{~V}$ AC.

Bridge Rectifier is used to rectify the ac voltage into pulsating DC voltage. Filter is used to convert pulsating DC voltage into pure DC voltage. $12 \mathrm{~V}$ Regulator is used to regulate the unregulated DC voltage into constant $12 \mathrm{~V}$ DC which voltage is used to operate relays and Digital control inputs.

\section{BLOCK DIAGRAM OF LOAD FREQUENCY CONTROL}

$5 \mathrm{~V}$ Regulator is used to regulate the regulated $12 \mathrm{~V}$ DC voltage into constant $5 \mathrm{~V} \mathrm{DC}$, which voltage is used to operate micro controller and analog inputs. Process analog input varies from 0 to $5 \mathrm{~V}$ DC. Relay is an electromagnetic based ON/OFF operation of process control. ADC is used to convert analog form of analog input DC voltage into binary 10-bit signal.

Process control digital switch input are connected to controller. Timer is used to control the process operation speed in microcontroller.

Flash memory is used to store the process control program and interaction with microcontroller and Timer.

Microcontroller is used to process the analog parameters and control the project with display the process the process parameters in LCD.LCD is used to cyclic display the process parameters in first line and any abnormal process/fault to be displayed in second line.

Relay Driver Circuit is used to interface the microcontroller outputs to process control output. 


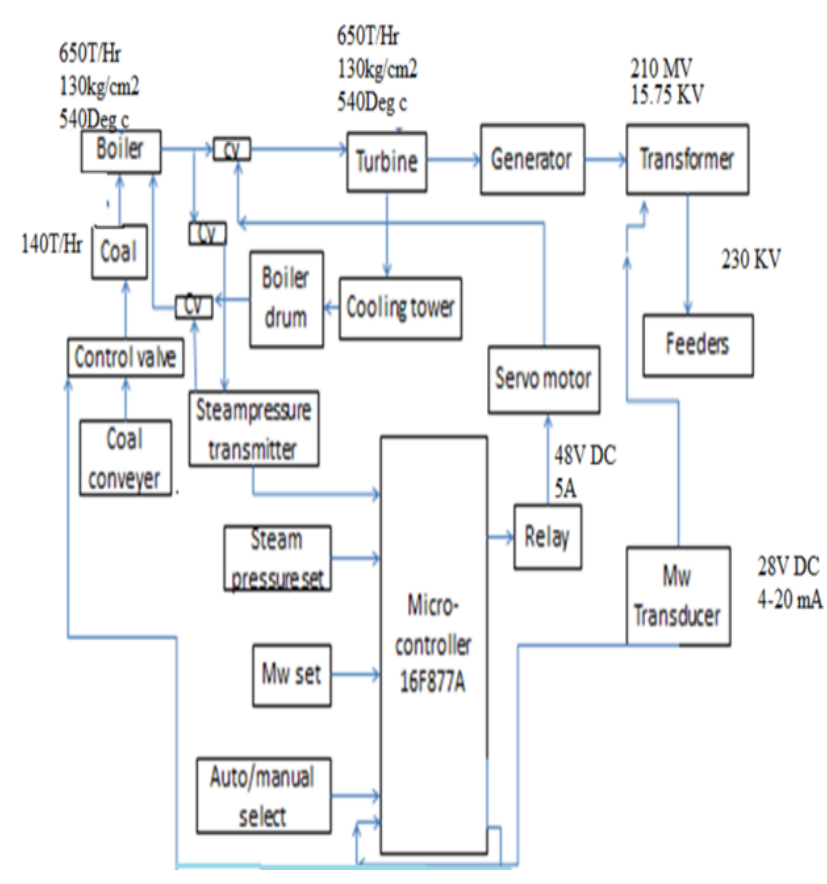

Fig-4 Block diagram of load frequency control

\section{CIRCUIT OPERATION}

Circuit diagram consist of one no. full wave bridge rectifier, one no. stand by full wave bridge rectifier, six no's of Optocoupler digital input circuits, seven no's of potential free relay operated contacts for digital outputs, one no 8-bit Flash memory type PIC micro controller and 16X2 line HD LCD display for display the analog output for the project parameters like Generator MW, MW Set, Main Steam Pressure Set and Actual Main Steam Pressure. Regulator IC-2(+5V DC) is used to regulate the Microcontroller and LCD power supply and IC1 (+12 V DC) is used to constant power supply to the Relay operating coils.Variable resistor VR1 is used to vary the contrast of LCD Display. Variable resistor VR2 is used to set the Generator Load Demand in MW. Variable resistor VR3 is used to indicate the Actual Generator Load in MW. Variable resistor VR4 is used to set the Main Steam Pressure in $\mathrm{Kg} / \mathrm{cm} 2$. Variable resistor VR5 is used to indicate the Actual Main steam Pressure coming from Boiler in $\mathrm{Kg} / \mathrm{cm} 2$.

Switches-1 \&2 are used to increase the Generator Load increase and decrease by manually. Switch-3 is used to Turbine Master Control in Auto or Manual, which control in Auto mode the Generator Load variation is based on the error of Main steam pressure Set value and Process value. The Main steam Pressure Process value exceeds the pre-programmed set value the Generator Load control goes to manual mode. Switch-6 is used to control the Plant operation in co-ordinate control mode i.e. the Generator Load control by the Generator Load demand and Load set value and also Total coal flow, Feed water flow control in Auto mode. Switch-4 is used to control the Rotor Excitation voltage control by Auto/Manual mode. Switch-5 is used to Generator Trip input to the controller. The SW7 is used to Master Reset of the microcontroller. One $4 \mathrm{MHZ}$ crystal oscillator is used to operate the speed of microcontroller. Two no's 22pf paper capacitors are used to reduce the noise in frequency generation of crystal oscillator.

The Green LED (L1) indicates "Power ON" of the circuit. 2 PIN connectors (CN1 to CN7) are used to inputs are given to the circuit and 3 PIN connectors (CN8 to CN14) are used to operate any external device like Circuit Breaker and motors. LED's (L2 to L8) are used to indicate the Relay ON of the circuit. LCD upper line to indicate the digital display of project parameters like Generator MW, MW Set, Main Steam Pressure Set and Actual Main Steam Pressure cyclically. LCD lower line to indicate any deviation in the Parameters like Main steam pressure process value and Actual Generator Load variation in preset value and Excitation voltage increases or decreases. Transistors (T1 to T7) are used to switching purpose of Relay coils.

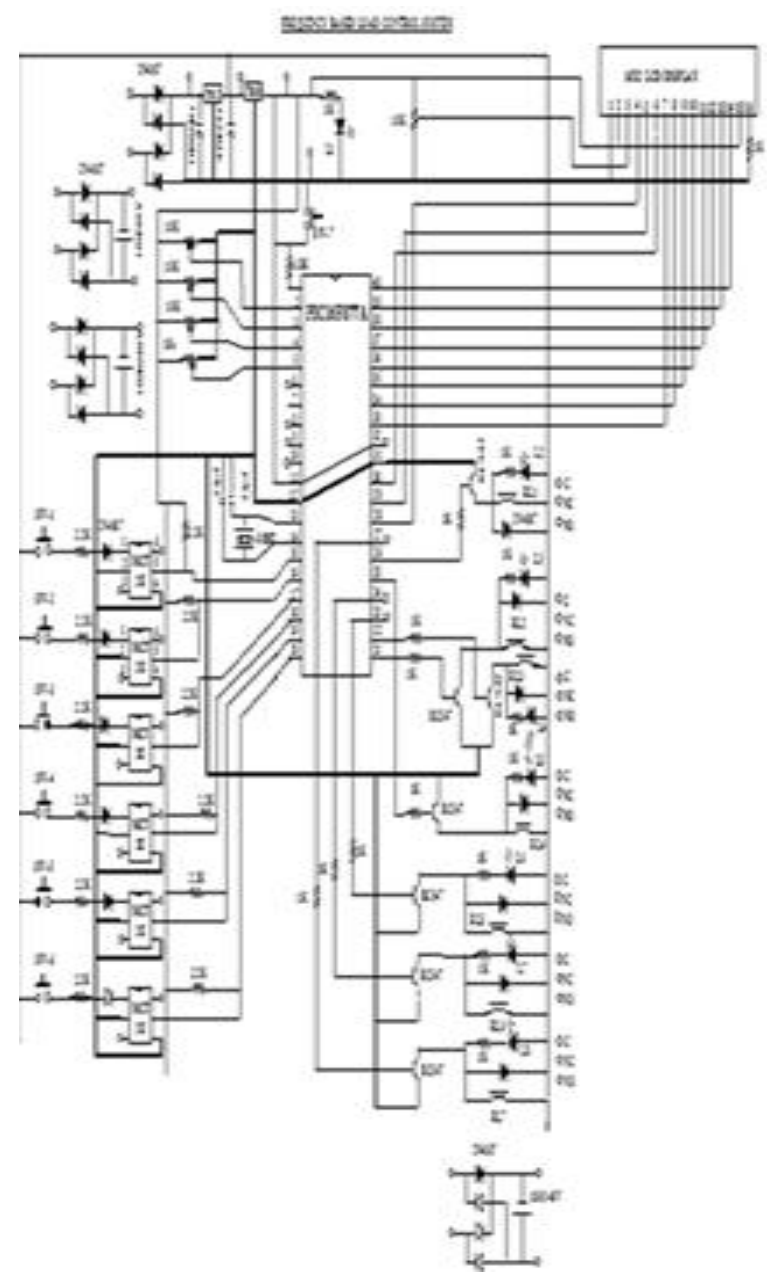

Fig-5 Circuit Diagram 


\section{CONCLUSIONS}

In our paper we present a speeder gear motor direction changes based on the error signal of Main steam pressure set and process value as per pre-programmed step command in the microcontroller in turbine master control mode. In co-ordinate control mode the speeder gear motor direction changes based on the error signal of Generator. In Co-ordinate control mode of operation, the coal and feed water flow will be increase or decrease as per the generator load. But in our project we are explained only information on coal flow and feed water flow. In future coal flow Inc /Dec and Feed water flow Inc / Dec commands are separately.

All grid connected generator to be implemented in this method to be first phase. Further changes in turbine mechanical governing system the grid frequency will take into our project. After that we are monitor the grid frequency variation and that variation is minimum for any grid disturbance, grid frequency will be accounted to our project in future renovation.

\section{REFERENCES}

[1] "Pros and Cons of Existing Frequency Regulation Mechanism in Indian Power Industry" S. K. Parida, Student Member, IEEE, S. N. Singh, Senior Member, IEEE, S. C. Srivastava, Senior Member, IEEE, P. Chanda, and A. K. Shukla 978-1-4244-17629/08/@2008 IEEE

[2] "An Indian Experience of Defense Against Blackouts and Restoration Mechanism followed" Subrata Mukhopadhyay, Senior Member, IEEE, Sushil K Soonee, Senior Member, IEEE, Sundaram $\mathrm{R}$ Narasimhan, and Rajiv K Porwal @2008 IEEE

[3] "A Genetic Algorithm Solution to the GovernorTurbine Dynamic Model Identification in MultiMachine Power Systems" George K. Stefopoulos, Student Member, IEEE, Pavlos S. Georgilakis, Member, IEEE, Nikos D. Hatziargyriou, Senior Member, IEEE, and A. P. Sakis Meliopoulos, Fellow, IEEE. Proceedings of the 44th IEEE Conference on Decision and Control, and the European Control Conference 2005 Seville, Spain, December 12-15,2005

[4] "Operating Experience of Regional Interconnections in India" Anjan Roy, S. A. Khaparde, Senior Member, IEEE, P. Pentayya, S. Usha, A. R. Abhyankar@ IEEE 2005

[5] "Coordinated Measurements for governor operations in the Southern Indian Grid" Geetha T, Mala E , Jayashankar V, Jagadeesh Kumar V, Sankaran P@ 16th IMEKO TC4 Symposium Sept. 22-24, 2008, Florence, Italy

[6] "A Genetic Algorithm Solution to the GovernorTurbine Dynamic Model Identification in MultiMachine Power Systems" George K. Stefopoulos, Student Member, IEEE, Pavlos S. Georgilakis, Member,
IEEE, Nikos D. Hatziargyriou, Senior Member, IEEE, and A. P. Sakis Meliopoulos, Fellow, IEEE. 44th IEEE Conference on Decision and Control, and the European Control Conference 2005 Seville, Spain, December 1215, 2005.

[7] "Frequency Response Characteristics of an Interconnected Power System - A case Study of Regional Grids in India" S.K. Soonee and S.C. Saxena, 6th International $\mathrm{R} \& \mathrm{D}$ conference on Sustainable Development of Water and Energy Resources-needs and Challenges - 13-16 Feb 2007 Lucknow UP India

[8] "Modelling of hydraulic governor-turbine for control stabilization" Yin Chin Choo, Kashem M. Muttagi, M. Negnevitsky @ EMAC 2007 pp C681-C698 2008

[9] "Robust Load Frequency Regulation in a New Distributed Generation Environment" H. Bevrani, Student Member, IEEE, Y. Mitani, Member, IEEE, and K. Tsuji, Member, IEEE, (C) 2003 IEEE Proceedin

[10] A.Molina-Garcia, F.Bouffard and D.S. Kirschen,decentralizeddemand-side ontribution to primary frequency control," IEEE Trans. on Power Systems, vol. 26, no. 1, pp. 411-419, 2001.

[11] D. S.Callaway and I. A. Hiskens, "Achieving controllability of electricloads," Proceedings of the IEEE, vol. 99, no. 1, pp. 184-199, 2011.

[12] M.Ilic and Q.Liu, "Toward sensing, communications and control architectures for frequency regulation in systems with highly variable resources," Control and Optimization Theory for Electric Smart Grids, New York: Springer, 2011.

[13] D.Trudnowski, M.Donnelly and E.Lightner, "Powersystem frequency and stability control using decentralized intelligent loads," in Proc. of the2005 IEEE T\&D Conf. Expo., Dallas, TX, May 2006.

[14] D.Trudnowski, M.Donnelly and E.Lightner, "Powersystem frequency and stability control using decentralized intelligent loads: Benefits and pitfalls," in Proc. of the 2010 IEEE Power and Energy Society General Meeting, Minneapolis, MN, Jul. 2010.

\section{BIOGRAPHIES}

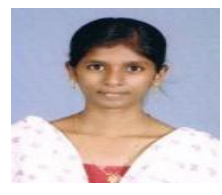

Ms.A.Nandhini was born on 15th September 1991 in Coimbatore. She has completed her UG degree B.E Electrical and Electronics Engineering in Karpagam College of Engineering during the year 2009 to 2013 under Anna University, Chennai. She is now currently pursuing her PG course specialized in Power Systems Engineering in Kalaignar Karunanidhi Institute of Technology under Anna University Chennai. Her main aim is to complete her doctorate degree within 5years. 


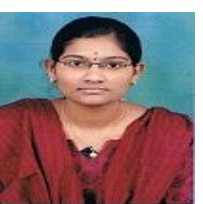

Ms.C.Deviabirami was born on $10^{\text {th }}$ October 1991 in Coimbatore. She has completed her UG degree B.E Electrical and Electronics Engineering in Karpagam College of Engineering during the year 2009 to 2013 under Anna University, Chennai. She is now currently pursuing her PG course specialized in Power Systems Engineering in Kalaignar Karunanidhi Institute of Technology under Anna University Chennai. Her main aim is to start an organization for the needy people and to help others then to get a doctorate degree.

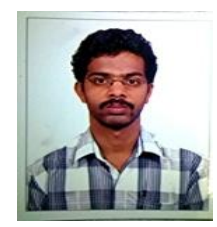

Mr.A.Manikandan was born on $24^{\text {th }}$ July 1988 in Palani. He has completed his UG degree B.E Electrical and Electronics Engineering in ACCET during the year 2006 to 2010 under Anna University, Chennai. $\mathrm{He}$ is now currently pursuing his PG course specialized in Power Systems Engineering in Kalaignar Karunanidhi Institute of Technology under Anna University Chennai. His main aim is to complete his doctorate degree within 5years and to publish more papers. 